\title{
A Fate Worse Than Death? How Biomarkers For ALZHEIMER's DisEASE COULD AFFECT END-OF-LIFE CHOICES
}

\author{
Rebecca Dresser, JD*
}

I. INTRODUCTION 651

II. RESEARCH ON AD BIOMARKERS ..................................... 653

III. Potential Responses to Biomarker Test Results. 657

A. Pre-Emptive Suicide. 657

B. Advance Treatment Refusals................................. 659

C. Advance Refusals of Food and Water ....................... 662

D. Advance Requests for Physician-Assisted Death .... 665

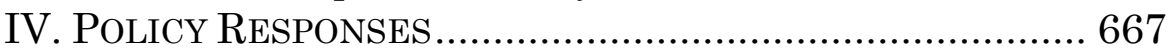

\section{INTRODUCTION}

For many years, scientists have searched for biological markers of the brain deterioration associated with the cognitive impairments characterizing Alzheimer's disease (AD). Although the search for useful biomarkers is ongoing, there is increasing evidence that certain brain changes indicate that a person is at relatively high risk of developing full-blown $\mathrm{AD}$.

Much of the research on $\mathrm{AD}$ biomarkers is motivated by the belief that successful treatment will require very early intervention in the disease process. Unfortunately, by the time people develop the memory and other behavioral problems that are associated with $\mathrm{AD}$, significant brain damage has already occurred. Biomarker tests could give patients and clinicians the opportunity to start drug and other treatments early, with the goal of slowing or stopping the deterioration that can eventually produce the clinical symptoms of AD. ${ }^{1}$

* Daniel Noyes Kirby Professor of Law, Professor of Ethics in Medicine, Washington University in St. Louis.

${ }^{1}$ Greg Miller, Stopping Alzheimer's Before It Starts, 337 ScIENCE 790 (2012). 
We can all hope that the medical promise of $\mathrm{AD}$ biomarkers becomes a reality. But it will take years to determine whether biomarker testing and early intervention produce clear health benefits. Currently available $\mathrm{AD}$ treatments are largely ineffective, and early therapeutic intervention remains unproven. Before effective treatment becomes available, many people tested for biomarkers could learn that they are at higher-thanaverage risk of developing $\mathrm{AD}$. Some people will appreciate this early warning, for it will give them an opportunity to get their affairs in order, take a long-desired vacation, and "have the kind of heartfelt talks with their children that that people often put off." 2

But for most people, the early warning will be disturbing news. Indeed, a few recent surveys suggest that $\mathrm{AD}$ is replacing cancer as the most-feared disease among Americans. ${ }^{3}$

As I discuss below, people alarmed at the possibility of losing their mental abilities might act to avoid a future with $\mathrm{AD}$. Some people might resort to pre-emptive suicide after receiving their biomarker test results. Others might make advance treatment directives refusing all life-sustaining interventions and even ordinary food and water if they become cognitively impaired and unable to make their own medical choices. People living in places that permit physician-assisted suicide and active euthanasia might seek medical assistance in dying, either right away or later, through an advance directive requesting death when they exhibit certain $\mathrm{AD}$ symptoms.

In short, $\mathrm{AD}$ biomarkers create new end-of-life issues for individuals, medical professionals, and policy makers. In Part I of this essay, I describe current research findings on $\mathrm{AD}$ biomarkers and their implications for end-of-life

\footnotetext{
2 Id. at 792.

3 See, e.g., Help for Alzheimer's Families, Americans Rank Alzheimer's as Most Feared Disease (Nov. 13, 2012), http://www.helpforalzheimersfamilies.com/alzheimers-dementia-careservices/alzheimers_feared_disease/; Mario Garrett, Fear of Dementia (May 11, 2013), http://www.psychologytoday.com/blog/iage/201305/feardementia.
} 
practices. Part II considers potential end-of-life responses to biomarker test findings and examines ethical and legal issues raised by those responses. Part III concludes with recommendations for clinicians and policy makers addressing the potential end-of-life impact of biomarker test findings.

\section{RESEARCH ON AD BIOMARKERS}

Scientists have not yet definitively established the causes of AD. Most experts trace the condition to a peptide called beta-amyloid and a protein called tau. The brains of people with symptomatic AD have pathological changes called "senile plaques," which are linked to beta-amyloid, and "neurofibrillary tangles," which are linked to tau. ${ }^{4}$ One major biomarker test involves measuring beta-amyloid and tau levels in a person's spinal fluid. ${ }^{5}$ The other major test uses magnetic resonance and positron emission tomography (PET) imaging to assess structural changes and the presence of beta-amyloid in the brain. ${ }^{6}$

4 Bruno Dubois et al., Revising the Definition of Alzheimer's Disease: A New Lexicon, 9 LANCET NeuRology 1118, 1119 (2010). Alzheimer's disease is a subset of the broader disease category called dementia. The biomarker tests I describe in this article apply to $\mathrm{AD}$ alone, not to all forms of dementia.

5 Stephanie Vos et al., Preclinical Alzheimer's Disease and Its Outcome: A Longitudinal Cohort Study, 12 LANCET NEURology 957 (2013).

6 Rahul Desikan et al., An Expanded Role for Neuroimaging in the Evaluation of Memory Impairment, 34 AM. J. NEURORADIOLOGY 2075 (2013). More AD biomarker tests will probably be developed in the future. A research group recently published study results showing that a blood test could predict onset of mild cognitive impairment or Alzheimer's disease with ninety percent accuracy. The study followed 525 cognitively normal adults aged seventy and older for five years. Mark Mapstone et al., Plasma Phospholipids Identify Antecedent Memory Impairment in Older Adults, 20 NATURE Medicine 415 (2014). As the researchers noted, however, the blood test will require additional evaluation before experts can determine whether it is sufficiently accurate for clinical use. Id. at 418 . Because such a test would probably be relatively inexpensive and simple to perform, it could make biomarker test results widely available to healthy older people interested in determining their AD risk. See Dena Davis, A Blood Test 
Scientists currently "lack ... a clear understanding of the relation between the neuropathological pattern of [Alzheimer's] disease and its clinical occurrence."7 Although most experts believe that the plaques and tangles associated with beta-amyloid and tau underlie AD symptoms, autopsies of cognitively normal older people reveal that many have plaques and tangles in their brains. ${ }^{8}$ This means that they either die of other causes before the brain pathology produces symptoms, or that other protective factors involving genes, environmental conditions, or brain or cognitive "reserve" prevent the brain pathology from affecting their thinking. ${ }^{9}$

The ongoing evaluation of $\mathrm{AD}$ research findings has generated new diagnostic classifications. Many experts use a classification called mild cognitive impairment to refer to people who have episodic memory impairment, but not the more severe deficits required for a diagnosis of $\mathrm{AD} .{ }^{10} \mathrm{~A}$ second classification, preclinical $\mathrm{AD}$, covers people who have a positive biomarker test but no detected memory impairment. ${ }^{11}$ A third diagnostic classification, sometimes called "prodromal AD" covers people who have both episodic memory impairment and a positive biomarker test. ${ }^{12}$ These

to Predict Alzheimer's Disease: What's the Elephant in the Room? BIOETHICS FORUM (Apr. http://thehastingscenter.org/Bioethicsforum/Post.aspx?id=6858\&blogid= 140.

7 Dubois et al., supra note 4, at 1121.

8 Lon Schneider, Organising the Language of Alzheimer's Disease in Light of Biomarkers, 9 LANCET NEUROLOGY 1044 (2010).

9 Reisa Sperling et al., Toward Defining the Preclinical Stages of Alzheimer's Disease: Recommendations from the National Institute on Aging-Alzheimer's Association Workgroups on Diagnostic Guidelines for Alzheimer's Disease, 7 Alzheimer's \& Dementia 280, 287 (2011). See also Kenneth Covinsky, Caution on Diagnosing Preclinical Alzheimer's Disease (July 15, 2011), BioETHICS ForUM, http://www.thehastingscenter.org/Bioethicsforum/Post.aspx?id=5454\&bl ogid=140 (noting that "autopsy finding[s] suggestive of Alzheimer's disease are commonly found in people who never had symptoms").

10 Sperling et al., supra note 9 , at 281.

11 Schneider, supra note 8, at 1044.

12 See Dubois et al., supra note 4, at 1122-23; Schneider, supra note 8 , at 1044. The term "prodromal" means a precursor indicating the onset of a disease process. 
three labels are applied to people who could eventually develop $\mathrm{AD}$ symptoms, but could also live for many years and perhaps the rest of their lives without doing so.

A study published in 2013 illustrates the situation. ${ }^{13}$ In this study, researchers evaluated 311 study participants sixty-five years or older over a five-year period. Eleven percent of the participants who scored within the normal range on cognitive testing, but had abnormal levels of betaamyloid, developed measurable cognitive decline five years after the test. Twenty-six percent of the participants with normal cognitive function, but abnormal levels of both betaamyloid and tau, showed some mental decline during the five-year period. These progression rates were much higher than the progression rates of participants in the control group, who were cognitively normal people with normal amyloid and tau levels. Just two percent of the participants in that group showed some mental decline after five years. ${ }^{14}$

Although study participants with positive biomarker tests and normal cognitive test scores were found to be at higher risk of developing $\mathrm{AD}$, most of these participants scored within the normal range on cognitive assessments five years after biomarker testing. The results were markedly different for study participants who initially had both abnormal beta-amyloid and tau levels and subtle mental decline. After five years, fifty-six percent of participants in that group received cognitive test scores consistent with $\mathrm{AD} .{ }^{15}$

Although the expert community is divided, there is increasing support for the use of biomarkers as a diagnostic aid when people are also exhibiting the cognitive symptoms characterizing AD. ${ }^{16}$ But many experts believe that because

\footnotetext{
13 Vos et al., supra note 5.

14 Id. at 960.

$15 I d$.

16 See, e.g., Keith Johnson et al., Appropriate Use Criteria for Amyloid PET: A Report of the Amyloid Imaging Task Force, the Society of Nuclear Medicine and Molecular Imaging, and the Alzheimer's Association, 9 Alzheimer's \& Dementia e1-e16 (2013). But lack of insurance coverage for such testing has so far limited its use. See Judith Graham, Debate Over Brain Scans and Alzheimer's, N.Y. Times (Feb. 12, 2013), http://newoldage.blogs.nytimes.com/2013/02/12/debate-
} 
biomarker tests for presymptomatic $\mathrm{AD}$ remain unproven, they should be performed only in a research context. ${ }^{17}$ At the same time, many cognitively normal and mildly impaired research participants, joined by individuals who are not participating in research, say they want access to the results of their biomarker tests. ${ }^{18}$ And a 2013 survey suggests that researchers may be moving to support return of test results to participants in $\mathrm{AD}$ biomarker research. ${ }^{19}$

Despite current uncertainty about the value of biomarker test results, more people are likely to learn their results in the coming years. Some researchers and physicians are likely to accede to research participants' and patients' requests to provide biomarker test results. Individuals obtaining their test results will receive probabilistic information. Although biomarker test results can indicate that a person is at relatively high risk of developing $\mathrm{AD}$, people diagnosed with preclinical $\mathrm{AD}$, mild cognitive impairment, and prodromal $\mathrm{AD}$ may never

over-brain-scans-and-alzheimers (reporting on Medicare decision declining to cover brain scans for diagnostic purposes, based on lack of evidence showing adequate health benefit). Medicare will cover one scan for individuals participating in clinical studies, however. Center for Medicare Services, Decision Memo for Beta Amyloid Positron Emission Tomography in Dementia and Neurodegenerative Disease (CAG-00431N) (Sept. 27, 2013), available at http://www.cms.gov/ medicare-coverage-database/details/nca-decisionmemo. aspx?NCAId=265.

17 E.g., Albert et al., The Diagnosis of Mild Cognitive Impairment Due to Alzheimer's Disease: Recommendations from the National Institute on Aging-Alzheimer's Association Workgroups on Diagnostic Guidelines for Alzheimer's Disease, 7 AlzheImeR's \& Dementia 270, 271 (2011); Guy McKhann, Changing Concepts of Alzheimer Disease, 305 JAMA 2458, 2459 (2011).

18 See J. Scott Roberts et al., Amyloid Imaging, Risk Disclosure, and Alzheimer's Disease, 3 Neurodegenerative Disease Mgmt. 219, 223 (2013); Melanie Shulman et al., Using AD Biomarker Research Results for Clinical Care: A Survey of ADNI Investigators, 81 NEURologY1114 (2013); Susan Gilbert, Support for Returning Results of Alzheimer's Disease Biomarker Research, Bionthics Forum (Aug. 28, 2013), http://thehastingscenter.org/Bioethicsforum/Post.aspx?id=6487\&amp;bl ogid $=140 \&$ terms $=$ Biomarker+and $+\% 23$ filename+*. html.

19 Shulman et al., supra note 18. 
develop the symptoms they fear. I turn now to the impact that $\mathrm{AD}$ biomarkers could have on end-of-life choices.

\section{Potential Responses to Biomarker Test Results}

\section{A. Pre-Emptive Suicide}

Pre-emptive suicide is one potential response to biomarker test results suggesting a high relative risk of AD. ${ }^{20}$ In a 2014 Journal of Medical Ethics article, bioethicist Dena Davis described and defended such a response. ${ }^{21}$ She gave several reasons why someone might prefer suicide over a probable future with AD. People might want their assets to go to relatives or charitable organizations, rather than to the workers and facilities that provide dementia care. People might also want to protect their loved ones from the burdens that $\mathrm{AD}$ can impose on others. ${ }^{22}$ People who see life with mental impairment as a "loss of self" 23 and an affront to their dignity may prefer death in the near future over longer survival with the prospect of $\mathrm{AD} .^{24}$

Davis also pointed out that unlike people diagnosed with other serious diseases like cancer or HIV, people with positive $\mathrm{AD}$ biomarker tests cannot postpone suicide until they actually experience unwanted symptoms. Suicide

20 See Richard Caselli et al., Public Perceptions of Presymptomatic Testing for Alzheimer Disease, Mayo Clin. Proceedings (2014), http://dx.doi.org/10.1016/j.mayocp.2014.05.016 (in online survey of people interested in $\mathrm{AD}$ research, 10.2 percent would seriously consider suicide if had biomarker evidence of AD). See also Brian Draper et al., Early Dementia Diagnosis and Risk of Suicide and Euthanasia, 6 ALZHEIMER's \& DEMENTIA 75 (2010) (discussing suicide possibility).

21 Dena Davis, Alzheimer Disease and Pre-Emptive Suicide, $40 \mathrm{~J}$. MED. ETHICs 543 (2014).

22 Of course, a person's decision to commit pre-emptive suicide could impose burdens on families, too.

23 Stephen Post, Physician-Assisted Suicide in Alzheimer's Disease, 45 J. AM. GERIATRICS SOC’Y 647 (1997).

24 Indeed, one philosopher has argued that the "soon-to-be demented" have a duty to commit suicide before losing their dignity as moral agents. Dennis Cooley, A Kantian Moral Duty for the Soon-to-BeDemented to Commit Suicide, 7 AM. J. Bioethics 37 (2007). 
takes relatively sophisticated planning, as well as a strong commitment. By the time $\mathrm{AD}$ symptoms develop, people are often unable to carry out a successful suicide; they may also lose interest in doing so. ${ }^{25}$ Davis observed that biomarker testing could enable more people to commit suicide before $\mathrm{AD}$ deprives them of the opportunity.

In a commentary on Davis's paper, ${ }^{26}$ I noted that currently available tests cannot give people definitive information about their futures. As I said earlier, many people with positive biomarker tests fail to progress to symptomatic AD. Will people be willing to end their lives based on an eleven percent or twenty-six percent possibility of $\mathrm{AD}$ in five years? Moreover, by the time people experience even mild mental decline (when the odds of progressing to $\mathrm{AD}$ become greater), they may no longer have the mental ability or the motivation to commit suicide. And even people who are able and willing to end their lives may have second thoughts about the wisdom of pre-emptive suicide once the choice becomes a real one. At that point, a life facing potential AD may seem to them preferable to no life at all. ${ }^{27}$

25 See Peter Rabins, Can Suicide Be a Rational and Ethical Act in Persons with Early or Pre-Dementia? 7 AM. J. BIoETHICS 47 (2007) (noting that lack of distress may be related to person's mental condition).

26 Rebecca Dresser, Pre-Emptive Suicide, Precedent Autonomy and Preclinical Alzheimer Disease, 40 J. MED. ETHICs 550 (2014).

27 People with life-threatening conditions are known to reevaluate their judgments about what constitutes a life worth living as their conditions advance, becoming more accepting of situations they previously thought would be unacceptable. People change their minds over time "because they cannot accurately imagine what they will want and how much they can endure in a condition they have not experienced." Jerome Groopman \& Pamela Hartzband, Advance Directives are the Beginning of Care, Not the End, ACP INTERNIST (July/Aug., 2012), available at http://www.acpinternist.org/archives/2012/07/gray.htm, archived at http://perma.cc/4V7F-NUNN. See also Sara Goering, What Makes Suffering "Unbearable and Hopeless"? Advance Directives, Dementia, and Disability, 7 AM. J. BiokTHICs 62 (2007) (noting that "our anticipatory beliefs fail to recognize our ability to adapt as well as how much the circumstances of impairment affect our ability to flourish"). 
Nevertheless, I agree with Davis's claim that biomarker tests could lead some people to commit suicide to avoid a future with $\mathrm{AD}$. There is some evidence suggesting that receiving an actual $\mathrm{AD}$ diagnosis raises the risk of suicide, although it appears that many of those suicides occur in people who are also clinically depressed. ${ }^{28}$ In my view, legal measures to completely prevent pre-emptive suicide would be morally unjustified, as well as impractical. Such measures would involve unacceptable and unworkable deprivations of liberty, such as confinement or continuous monitoring of individuals at risk for $\mathrm{AD}$. At the same time, however, certain policy measures could discourage impulsive and uninformed suicide attempts based on $\mathrm{AD}$ biomarker results. In the concluding part of this essay, I describe such measures.

\section{B. Advance Treatment Refusals}

Advance treatment directives refusing all life-sustaining interventions are another potential response to $\mathrm{AD}$ biomarker testing. Through an advance directive, mentally competent individuals can make choices about the future treatment they want to receive as incompetent patients. They can, for example, give instructions that they should not receive any treatment for life-threatening medical conditions if they develop $\mathrm{AD}$ and can no longer make contemporaneous treatment decisions.

Positive biomarker test results could provoke some people to make advance directives refusing any treatment that could extend their lives with AD. Since the 1990s, there has been a lively discussion about the ethical issues raised by this kind of advance directive. According to some scholars, such as Ronald Dworkin, directives like this should be followed, even if they conflict with a patient's contemporaneous best interests. ${ }^{29}$ Dworkin argued that the competent person's values and preferences have greater

28 See Draper et al., supra note 20 , at $79-80$ for a review of the literature.

29 Ronald Dworkin, Life's Dominion: An ARgument About ABORTION, EUTHANASIA, AND INDIVIDUAL FREEDOM 231 (1993). 
moral weight than do the welfare interests of a mentally incapacitated individual. ${ }^{30}$ Thus, he wrote, the law should permit people "who are repelled by the idea of living demented, totally dependent lives, speaking gibberish" to direct that "if they become permanently and seriously demented and then develop a serious illness, they should not be given medical treatment except to avoid pain." ${ }^{31}$

In defending this view, Dworkin gave an example of a case in which such a directive should be followed. The case involved a patient named Margo. Margo had been the subject of an article by a medical student, Andrew Firlik, who had come to know Margo in the course of his training. ${ }^{32}$ Margo appeared to enjoy music and art therapy classes; she also seemed pleased when Firlik visited, although she never called him by name. Although she had lost much of her memory and needed assistance with many activities, Firlik concluded that Margo was "undeniably one of the happiest people I have known." 33

Dworkin asked readers to imagine that Margo had previously prepared an advance directive stating that if she developed $\mathrm{AD}$, "she should not receive treatment for any other serious life-threatening disease she might contract." ${ }_{4}$ That directive should govern Margo's care, Dworkin declared, even if she was currently living a life that gave her satisfaction and pleasure. ${ }^{35}$ Her wishes as a competent person should take priority over her current interests as an incompetent dementia patient, he argued. ${ }^{36}$

In contrast, a second group of scholars supports limiting the power that advance directives have over $\mathrm{AD}$ patient

\footnotetext{
$30 I d$.

31 Id. The quotation suggests that pain avoidance was the one welfare interest of dementia patients that Dworkin believed should be protected. For analyses similar to Dworkin's, see Dena Davis, supra note 21; Norman Cantor, Prospective Autonomy: On the Limits of Shaping One's Postcompetence Medical Fate, 8 J. ContemP. Health L. \& POL'Y 13 (1992).

32 Andrew Firlik, Margo's Logo, 265 J. AM. MED. ASS'N 201 (1991).

33 Id.

34 DWORKIN, supra note 29, at 226.

35 Id.

36 Id.
} 
care. This group acknowledges that advance directives can be useful in addressing treatment questions, for directives often refuse treatment that would not serve the patient's current welfare interests. For example, advance directives refusing burdensome interventions like chemotherapy and surgery often promote an AD patient's welfare, because such interventions impose pain and distress on a person who cannot understand or remember why they are being done. But sometimes a minimally burdensome treatment, such as an oral antibiotic, can allow an $\mathrm{AD}$ patient like Margo to continue a life of apparent contentment. Such patients no longer remember the values that led them to refuse treatment in this situation, and they remain able to engage in activities and interactions that they enjoy. ${ }^{37} \mathrm{I}$ and others are unconvinced that an individual's former wish to avoid such a state should always take priority over her current interests in continuing a life that she appears to value. ${ }^{38}$

In other contexts, law and policy recognize that people with mental disabilities can have lives of meaning and worth. The legal and ethical question is whether the rules governing advance directives should incorporate, or reject, this moral judgment. Should competent people have absolute authority over the future care they receive as $\mathrm{AD}$

37 Philosopher Agnieszka Jaworska developed the concept of "capacity to value" to describe some $\mathrm{AD}$ patients' retention of a basic capacity for autonomy. Jaworska believes that such patients' contemporaneous preferences and interests are a form of autonomy that deserves respect. See Agnieszka Jaworska, Respecting the Margins of Agency: Alzheimer's Patients and the Capacity to Value, 28 PHIL. \& PUB. AFF. 105 (1999).

38 See Rebecca Dresser, Dworkin on Dementia: Elegant Theory, Questionable Policy, 25 Hastings Center ReP. 32 (Nov.-Dec. 1992). For other accounts defending limits on advance directives in cases involving some conscious AD patients, see Jaworska, supra note 37; Allen Buchanan, Advance Directives and the Personal Identity Problem, 17 PHIL. \& PUB. AFF. 277 (1988). For a middle-ground position, see Paul Menzel \& Bonnie Steinbock, Advance Directives, Dementia, and Physician-Assisted Death, 41 J. L. MED. ETHICs 484, at 498 (arguing for similar judgments regarding advance directives for physician-assisted death and refusal of life-sustaining treatment in dementia). 
patients, or should legal rules and professional standards set limits on that authority?

To date, courts and other authorities have not directly addressed the issue I have described. Relatively few people make advance treatment directives containing precise instructions for future treatment, and I have not heard or read about an actual directive like the one Dworkin described. 39 A few courts have mandated medical nutrition and hydration for conscious incapacitated patients who previously made informal remarks suggesting that they would oppose such treatment. But none of these cases involved a formal advance directive refusing all lifesustaining measures as an incapacitated patient. ${ }^{40}$

In the coming years, clinicians and courts are likely to encounter advance directives presenting conflicts between a dementia patient's past wishes and current interests. The baby boom generation is aging, and many in this group are both insistent on controlling their future medical care and terrified by the prospect of dementia. The results of $\mathrm{AD}$ biomarker tests could lead some of them to make a directive like the one Dworkin envisioned.

\section{Advance Refusals of Food and Water}

People disturbed by their AD biomarker test results might also look to a new form of advance directive to avoid life with dementia. In a recent article, Paul Menzel and Collette Chandler-Cramer argue that clinicians and legal authorities should recognize advance refusals of not only life-prolonging medical interventions, but also of spoonfeeding and other assistance with ordinary eating and

39 See generally Muriel Gillick, Reversing the Code Status of Advance Directives? 362 New EnGL. J. MED. 1239 (2010) (reviewing shortcomings of advance directives and suggesting reforms).

40 See Rebecca Dresser, The Conscious Incompetent Patient, 32 Hastings Cent. ReP. 9 (May-June 2002); Rebecca Dresser, Still Troubled: In re Martin, 26 HASTINGs CENT. ReP. 21 (July-Aug. 1996) (describing two representative cases). 
drinking. ${ }^{41}$ This advance directive would be a valuable tool for individuals seeking to avoid a lingering death with dementia, they say.

The directive Menzel and Chandler-Cramer propose would apply only to patients in the late stages of $\mathrm{AD}$, when patients require assistance with nearly every activity, including eating and drinking. These authors see advanced dementia as the final stage of life. By the time patients become "indifferent" to food, they are unable to walk, converse, or recognize their loved ones. At that point, Menzel and Chandler-Cramer contend, the patients' interests in survival are small enough that the decision to withhold food and water fails to present a threat to their welfare.

Menzel and Chandler-Cramer offer several justifications for their proposal. Besides arguing that the law should respect the competent individual's interest in controlling future care, they describe evidence indicating that death due to lack of nutrition and hydration is relatively comfortable. The law permits competent patients to hasten death by refusing to eat and drink, they observe, so why not allow people to do so in advance?

I agree that such a directive would be appealing to people intent on avoiding the lengthy decline and severe incapacities that characterize late-stage dementia. But in a commentary on the proposal, I raised questions about its legality. ${ }^{42}$ Although the law permits competent patients to refuse ordinary food and water, no statute or court decision recognizes the competent person's right to make an advance directive refusing assistance with eating and drinking. ${ }^{43}$ Imposing tube feeding on an objecting competent patient is a clear and massive intrusion on that person's liberty and bodily integrity. In contrast, giving a dementia patient help

41 Paul Menzel \& Colette Chandler-Cramer, Advance Directives, Dementia, and Withholding Food and Water by Mouth, 44 HASTINGS CENTER REP. 23 (May-June 2014).

42 Rebecca Dresser, Toward a Humane Death with Dementia, 44 HASTINGS CENTER REP. 38 (May-June 2014).

43 See Thaddeus Pope \& Amanda West, Legal Briefing: Voluntarily Stopping Eating and Drinking, 25 J. CLIN. ETHICS 68 (2014). 
with ordinary eating and drinking fails to constitute such a serious intrusion, even if the individual previously refused such help. It is not clear that legal authorities will equate advance refusals of assistance with eating and drinking with competent patients' contemporaneous refusals of food and water.

The proposal also raises ethical concerns, for it could compromise the welfare of some dementia patients. Menzel and Chandler-Cramer describe a patient named Shari as one candidate for their approach. Before she was diagnosed with $\mathrm{AD}$, Shari made an advance directive refusing assisted feeding as an advanced AD patient. Shari now has advanced $\mathrm{AD}$, is incontinent, and cannot "walk, feed herself, or chew and swallow." 44 With spoon-feeding and encouragement, however, she swallows nutritional smoothies. And Shari "occasionally appears to get pleasure from the smoothies and she seldom expresses distress or discomfort." 45

Despite that fact that Shari accepts nourishment, Menzel and Chandler-Cramer believe that nourishment should be withheld based on her advance directive. My concern is that a patient like Shari could experience distress and discomfort if no one offers her the smoothies she is accustomed to receiving. Shari is not an AD patient who resists eating or experiences choking or other distressing effects when she tries to swallow. Withholding food and water from such a patient is defensible on grounds that it maintains the patient's comfort. But that defense doesn't apply in cases like Shari's. Before allowing withholding in such cases, it will be necessary to examine the burdens withholding could impose on a patient like Shari.

Despite these concerns, people with positive AD biomarker test results could advocate for the right to make directives like the one Menzel and Chandler-Cramer propose. With the availability of biomarker test results, clinicians and policy makers could face increased pressure to permit and enforce such directives.

${ }^{44}$ Menzel \& Chandler-Cramer, supra note 41, at 23.

45 Id. 


\section{Advance Requests for Physician-Assisted Death}

Requests for physician-assisted death are an additional potential response to $\mathrm{AD}$ biomarker testing. Legal authorities in the United States have not recognized a right to medically assisted death for anyone at risk of or diagnosed with $\mathrm{AD}$. A few states have legalized physicianassisted suicide, but only for terminally ill competent patients with six months or less to live. 46 It is a different story in the Netherlands, however. That nation has a liberal law governing access to medically assisted death, one that permits physician-assisted suicide and active euthanasia in a wide range of situations.

Two requirements in the Dutch law would appear to disqualify $\mathrm{AD}$ patients from eligibility for assisted death. The law permits physicians to respond only to requests that are "voluntary and well considered" made by people experiencing "the situation as 'unbearable' and one of "hopeless suffering."' 47 Studies have found that most Dutch physicians are unwilling to follow advance directives requesting euthanasia for $\mathrm{AD}$, citing "difficulty determining the suffering of the patient and determining the exact moment" to carry out the advance directive. 48 Coping mechanisms lead many early AD patients to downplay the problems they are experiencing, and as the disease progresses, people become completely unaware of those problems. As one group of Dutch clinicians put it, in the typical patient, "the realization of having dementia is

46 See Erik Eckholm, 'Aid in Dying' Movement Takes Hold in Some States, N.Y Times, Feb. 7, 2014, http://www.nytimes.com/2014 /02/08/us/easing-terminal-patients-path-to-death-legally.html\#.

47 See Cees M. P. M. Hertogh et al., Would We Rather Lose Our Life Than Lose Our Self? Lessons From the Dutch Debate on Euthanasia for Patients with Dementia, 7 AM. J. Bioethics 48, 49 (2007) (describing Dutch law).

48 See id. at 50-51; Marike E. de Boer et al., Advance Directives for Euthanasia in Dementia: Do Law-Based Opportunities Lead to More Euthanasia? 98 Health Pol'y 256, 260-61 (2010). See also Ron L. P. Berghmans, Ethics of End-of-Life Decisions in Cases of Dementia: Views of the Royal Dutch Medical Association with Some Critical Comments, 13 Alzheimer's Disease \& Associated Disorders 91 (1999) (discussing these problems). 
progressively lacking from the patient's subjective experience and hence it is impossible for someone in an advanced stage of dementia to appreciate the situation as "unbearable and hopeless." 49

Nevertheless, Dutch physicians have performed euthanasia for people in the early stages of AD.50 And in 2011, a woman with advanced AD was euthanized based on a request contained in her advance directive, a directive that was made five years after her $\mathrm{AD}$ diagnosis. ${ }^{51}$ Officials approved euthanasia in these cases, despite doubts about the decision-making capacity of the $\mathrm{AD}$ patients and questions about whether the patients were actually experiencing unbearable suffering. 52

In light of this nation's conservative position on assisted death, U.S. clinicians and officials are unlikely to face these issues in the near future. But given the "Alzheimerphobia" 53 that also exists in this country, U.S. clinicians and officials may eventually confront demands to allow medically assisted death for people with early-stage $\mathrm{AD}$, as well as for people in later stages of the disease based on their requests contained in advance directives. ${ }^{54}$ The

49 Hertogh et al., supra note 43, at 51.

50 See Tony Sheldon, Dementia Patient's Suicide Was Lawful, Say Dutch Authorities, 343 BMJ d7510 (2011) [hereinafter Sheldon, Dementia Patient's Suicide]; Tony Sheldon, Dutch Committee Approves Euthanasia for a Patient with Alzheimer's Disease, 330 BMJ 1041 (2005) [hereinafter Sheldon, Dutch Committee].

51 See Dementia Patient's Suicide, supra note 51.

52 See Assisted Dying in Alzheimer's Disease: The Dutch Experience, 4 LANCET NEUROLOGY 389, 389 (2005) (raising these questions).

53 Draper et al., supra note 20, at 76.

54 See, e.g., Menzel \& Steinbock, supra note 38, at 484; Janice Schuster, Invitation to a Dialogue: Legalizing Aid in Dying, N.Y. TIMES, Mar. 25, 2013, http://www.nytimes.com/2013/03/27/opinion/invitation-toa-dialogue-legalizing-aid-in-dying.html (discussing possibility of assisted death for dementia patients). Janet Adkins, the first person committing suicide with the assistance of Michigan doctor Jack Kevorkian, had been recently diagnosed with AD. See Timothy Egan, As Memory and Music Faded, Oregon Woman Chose Death, N.Y. Times, June 7, 1990, http://www.nytimes.com/1990/06/07/us/as-memory-andmusic-faded-oregon-woman-chose-death.html. 
availability of $\mathrm{AD}$ biomarker tests could increase public support for such measures.

\section{POLICY RESPONSES}

As I noted earlier, researchers and clinicians have in the past failed to disclose biomarker test results to research participants and patients, citing the uncertain meaning of the results. But this approach is under attack by people who have had or are interested in having the tests, and by health professionals who believe that test results are sufficiently informative to support disclosure. Researchers and clinicians are becoming more open to disclosing results to people who want to know their $\mathrm{AD}$ biomarker status. ${ }^{55}$

The next step is for researchers, clinicians, and policy makers to develop an adequate approach to disclosure of biomarker test results. Potential recipients of test results must understand the risks and burdens, anticipated benefits, and alternatives to biomarker testing. ${ }^{56}$ They must understand, for example, the risk that a positive biomarker test result in their medical record would expose them to workplace or insurance discrimination. ${ }^{57}$

Two features of biomarker test results are particularly important, yet challenging, to address in the disclosure process. Health professionals must teach people about the limited predictive power of biomarker test results, and about the significant possibility that people with positive test results will not progress to $\mathrm{AD}$ for a many years, if ever. ${ }^{58}$ This education is necessary to prevent people from making uninformed end-of-life decisions based on their test results.

Health professionals must also address the fears people have about AD. One expert group has commented that "the lived experience of dementia differs from the imagined

55 See infra pp. 5-6.

56 See Draper et al., supra note 20, at 81; Jason Karlawish, Addressing the Ethical, Policy, and Social Challenge of Preclinical Alzheimer Disease, 77 Neurology 1487, 1489 (2011).

57 See Roberts, supra note 18, at 224.

58 Id. 
experience." ${ }^{59}$ According to another expert who has worked with $\mathrm{AD}$ patients for thirty years, people who say they would not want to live with dementia are "overestimating the importance of cognition in their lives and underestimating the importance of interpersonal relationships."60 Other experts have made similar observations, ${ }^{61}$ with some noting that patients' families are often more distressed than are the patients themselves. ${ }^{62}$ Indeed, empirical evidence suggests that many people with $\mathrm{AD}$ report and appear to have a good quality of life. ${ }^{63}$ As a group of Dutch researchers noted, "[f]urther exploration of the lived experience of dementia is urgently needed to counterbalance the natural, but nonetheless one-sided ideas of elderly people who are scared of dementia." 64

At the same time, depression and anxiety are not uncommon among people with AD. ${ }^{65}$ Although certain $\mathrm{AD}$ patients don't appear to have a good quality of life, their burdens can be lessened when they receive care that is tailored to their needs. British psychologist Tom Kitwood pioneered a person-centered approach to dementia care that is now being adopted in some dementia care settings. ${ }^{66}$ The

59 Draper et al., supra note 20, at 77.

60 Rabins, supra note 25, at 49.

61 See, e.g., Alan Jacques \& Graham JaCkson, Understanding DEMENTIA 197-99 (3d ed. 2000) (patients unlikely to be aware of changes in their abilities or humiliated by their dependence).

62 See, e.g., Diane Meier \& Christine Cassel, Nursing Home Placement and the Demented Patient, 104 Annals Internal Med. 98, 102 (noting that families' distress can often exceed that of patients; patients "can appear to be at peace and secure in a safe familiar environment").

63 See Draper et al., supra note 20, at 77 (summarizing findings on AD patients' quality of life). See also Goering, supra note 27, at 62 (noting that stigma and fear can distort views of what life with dementia and disability is really like).

64 Hertogh et al., supra note 47, at 54.

65 See Draper et al., supra note 20, at 77.

66 See, e.g., Tom Kitwood \& Kathleen Bredin, Towards a Theory of Dementia Care: Personhood and Well-Being, 12 AGEING \& SocIETY 269 (1992). See also Steven Sabat, Voices of Alzheimer's Disease Sufferers: A Call for Treatment Based on Personhood, 9 J. Clinical Ethics 35 (1998) (presenting similar view). For a description of how the approach 
approach asks others to value what people with dementia are able to do, such as live in the moment and respond to others with an honesty unseen among cognitively "normal" people. ${ }^{67}$ By trying to see the world through the eyes of a person with $\mathrm{AD}$, caregivers seek to provide an environment that is pleasant and comfortable for that person. ${ }^{68}$

People with positive biomarker tests need an accurate picture of what life with $\mathrm{AD}$ involves before they make endof-life choices based on their test results. Although AD is a frightening prospect, some of that fear is based on a lack of understanding of what life can be like for people with AD.

Implementing Kitwood's patient-centered care approach is part of a broader national and worldwide task: to respond to the growing population of people affected by $\mathrm{AD}$ and other forms of dementia. This demographic development presents immense ethical, medical, financial, legal, and social challenges, in this country and the rest of the world. 69 Determining the proper role of $\mathrm{AD}$ biomarkers in end-of-life choices will be one of these challenges.

works in practice, see Rebecca Mead, The Sense of an Ending, NEW YORKER, MAY 20, 2013.

67 See Nuffield Council on Bioethics, Dementia: Ethical Issues (2009), http://nuffieldbioethics.org/dementia (describing community's ethical obligation to accept people with dementia and provide services adapted to their needs). See also Sarah Walker-Robinson, Let's Talk (Some More) about Dementia, June 17, 2014, http://blog.nuffieldbioethics.org/?p=1279 (describing efforts to make society more "dementia-friendly").

68 See JACQUES \& JACKSON, supra note 61, at 200-01; Mead, supra note 66 .

69 See Michael Hurd et al., Monetary Costs of Dementia in the United States, 368 New ENG. J MeD. 1326 (2013); Thomas Montine \& Eric Larson, Late-Life Dementias: Does this Unyielding Global Challenge Require a Broader View? 302 J. AM. MED. Ass'N 2539 (2009). 